\title{
Engineering nitrogen fixation
}

from Andrew Johnston

\section{A conference entitled Genetic Engineering for Nitrogen Fixation, organised by $\mathrm{Dr} \mathrm{A}$. Hollaender, was held at Brookhaven National Labor- atories, Upton, New York, on 13- 17 March, 1977.}

THE current interest in biological nitrogen fixation reflects the desire that an increased amount of the fixed $\mathrm{N}$ in crops should come from this source rather than from energy-expensive fertiliser. The aim of this meeting was to see whether such a goal might be achieved by genetic techniques. Most reports dealt with the status of current research in different aspects of nitrogen fixation, but attention was given to systems whose development might conceivably lead to an extension of the range of nitrogen-fixing organisms.

D. Helinski (University of California, San Diego) reviewed the methodology and uses of DNA cloning. He made the point that to date only the $\mathrm{P}$-group $\mathrm{R}$ plasmids can be transferred to many bacteria of agronomic importance. However, their promiscuity and relatively large size make them unsuitable as cloning vehicles and he described methods by which the ability to replicate in a wide range of bacteria might be transferred to more appropriate vehicles.

Detailed mapping of nitrogen fixation (nif) genes has been caried out only in Klebsiella pneumoniae. C. Kennedy (ARC Unit of Nitrogen Fixation, Sussex) showed by transduction that nif genes fall into two closely linked clusters separated by a 'silent' region. Complementation tests have defined a new nif gene (nifL) which has the attributes of a controlling gene since the mutant is partially dominant and synthesises no nitrogenase components. F. Ausubel (Harvard University) reported that the nif cluster proximal to his $D$ could be cloned on the plasmid pMB9.

Turning to the genetics of other nitrogen-fixing bacteria A. Johnston (John Innes Institute, Norwich) demonstrated that the $\mathbf{R}$ plasmid R68.45 could promote chromosomal recombination in Rhizobium species and that stable recombinants could be formed in crosses between species. A single circular chromosome for $R$. leguminosarum was reported. In Azotobacter vinelandii many nif mutants have been characterised biochemically, but genetic analysis has been lacking. W. Brill (University of Wisconsin, Madison) reported that nif genes in these species could be transferred by transformation, but in contrast to $K$. pneumoniae they were not closely linked. More suprising was the fact that nif $^{+}$transformants were obtained with DNA obtained from Rhizobium.

There have been several reports that plant lectins may determine the specificity of interactions between Rhizobium and legumes. D. Bauer (C. Kettering, Yellow Springs) showed that not all strains of $R$. japonicum bind the lectins of its host, the soybean. Those that did not could however, be induced to do so by whole soybean roots. This observation may resolve some of the discrepancies in the literature in which binding of lectins to some infective strains of Rhizobium has not been observed.

The symbiosis between Azolla and Anabaena has been used as a source of fixed nitrogen in Asian rice paddies for centuries. B. Rains (University of California, Davis) demonstrated that ail equivalent of $90 \mathrm{~kg} \mathrm{ha}^{-1} \mathrm{yr}^{-1}$ may be contributed by this symbiosis. It is not possible however to cultivate the blue-green alga outside the plant so the goal of breeding for increased levels of fixation remains a distant one.

The role of Spirillum as a significant contributor of fixed nitrogen remains enigmatic. Although it was shown by J. Dobereiner (Embrapa, Brazil) to get into maize roots, it appears to contribute little to the nitrogen input of this plant though it may do so with some tropical grasses and wheat varieties.

The supply of energy to nitrogenfixing systems was considered by several speakers to be a major limitation to increasing levels of fixation. R. Valentine (University of California, Davis) estimated that in the 'artificial nodule' in which $\mathrm{NH}_{4}{ }^{+}$-excreting strains of $K$. pneumoniae were grown, about 20 molecules of ATP are required for every molecule of nitrogen fixed, although this ratio varied depending on environmental factors. Invariably $\mathbf{H}_{2}$ is liberated during the reduction of $\mathrm{N}_{2}$, but some of this energy loss may be recouped if a hydrogenase is present. H. Evans (Oregon State University, Corvallis) discussed the importance of this reaction in root nodules and pointed out that a particularly effective strain of $R$. japonicum has hydrogenase activity.

If nif genes are to be introduced into new hosts suitable vectors must first be obtained. Evidence that DNA from the crown-gall bacterium Agrobacterium tumefaciens does in fact integrate into plant DNA was given by E. Nester (University of Washington, Seattle).
DNA isolated from crown-gall tissue specifically hybridised with one particular fragment derived from SmaI digestion of the large tumour-inducing (Ti) plasmid of $A$. tumefaciens. This integrated plasmid is present in about 20 copies per plant cell and is transcribed in crown gall tissue, since RNA from this source hybridises specifically with it. These results were complemented by those of D. Schell (University of Ghent), who found that in some cases Ti plasmids contain large hairpin loops characteristic of some translocating sequences. In a strain which had lost both the ability to degrade octopene and to induce tumours one of the loops (length $40 \mu \mathrm{m}$ ) was missing.

The use of plant viruses as possible vectors was discussed by $\mathbf{R}$. Meagher (University of Georgia, Athens). $\mathrm{He}$ showed that when the DNA of cauliflower mosaic virus was cloned in $E$. coli extra proteins were synthesised, but that none corresponded to normal virus proteins, which confirms the difficulties of obtaining accurate transcription and translation of eukaryote DNA in prokaryotes.

However, it was emphasised at the meeting that the most promising strategy for improving the economic contribution of biological nitrogen fixation to agriculture probably lies in the development of better types of already existing nitrogen fixation systems.

The conference also considered some of the legal, ethical and environmental implications of the scientific contributions. These discussions were strongly influenced by the present concern in the United States about the potential hazards of recombinant DNA research. This meant that while there was a general consensus of opinion that production of more efficient nitrogenfixing plants and bacteria was desirable, a number of people were concerned about the possible environmental impact of such organisms even if they were formed by classical methods of gene transfer.

\section{Positronium spin conversion}

\section{from P. W. Atkins}

A TECHNIQUe which can detect minute concentrations of triplet states of molecules in gases at normal pressures may have important applications in detecting small concentrations of some air pollutants. The technique depends on positronium spin conversion, a new development of the well-known inter- 